\title{
Population ecology size and habitat preference of the ghost orchid Didymoplexis pallens in Bogor Botanic Gardens, Indonesia
}

\author{
RIZMOON NURUL ZULKARNAEN", R. VITRI GARVITA, HARY WAWANGNINGRUM, \\ KARTIKA NING TYAS \\ Research Center for Plant Conservation and Botanic Gardens (Bogor Botanic Gardens), Indonesian Institute of Sciences. Ir. H. Juanda No. 13 Bogor \\ 16122, West Java, Indonesia. Tel./fax.: +62-251-8322-187, `email: rizmoon.zulkar@gmail.com
}

Manuscript received: 25 January 2020. Revision accepted: 17 April 2020

\begin{abstract}
Zulkarnaen RN, Garvita RV, Wawangningrum, H, Tyas KN. 2020. Population ecology size and habitat preference of the ghost orchid Didymoplexis pallens in Bogor Botanic Gardens, Indonesia. Biodiversitas 21: 2056-2061. Didymoplexis pallens is a terrestrial orchid that has leafless characteristics. The population ecology of $D$. pallens is still not widely known because it only grows in certain areas and at certain times. This study aims to know the population ecology and habitat preference of $D$. pallens. The study was conducted in Bogor Botanic Gardens where D. pallens occurred naturally. The research method uses purposive sampling by establishing observation plots around bamboo collections in the garden. The results showed that $D$. pallens had a large population around specific bamboos, such as Gigantochloa verticillate, Gigantochloa atroviolacea and Dendrocalamus giganteus. In addition, the presence of D. pallens populations was strongly influenced by the presence of other plants that compete around it and light intensity. The Principal Component Analysis revealed there are two components of the abiotic factor that influenced the existence of $D$. pallens, i.e. the first component consisting of coverage, air humidity, temperature, and soil humidity. The second component consisting of litter thickness and soil $\mathrm{pH}$.
\end{abstract}

Keywords: Didymoplexis pallens, ecological requirements, protected area, leafless orchid

\section{INTRODUCTION}

Didymoplexis is a small genus of the Orchidaceae family. There have been 20 species described from this genus with distribution in tropical Africa, Madagascar, Southeast Asia, India, Pacific Island, North Australia, Ryukyu Island, and Taiwan (Su 2000; Pridgeon et al. 2005). It is classified as a terrestrial leafless orchid since the growth of Didymoplexis will only occur above the ground in the flowering and fruiting stage. As such, the orchids in this genus are often known as one of the ghost orchid groups. This orchid is also included in mycoheterotrophic plants which obtain carbon from a symbiotic relationship with a fungus (Leake 1994, Cameron and Leake 2007, Merckx 2013a).

In Java, there are only 6 species from the genus of Didymoplexis, 5 of which are endemic to West Java (Bogor), including D. cornuta, D. minor, D. flexipes, D.striata, and D. oberoniformis (Mursidawati 2004; Merckx et al. 2013b). The other species that is commonly found is $D$. pallens. The distribution of $D$. pallens extends from India, West Bengal, Burma, Thailand, to Malaysia and Indonesia (Hooker 1894; Rao et al. 1979; Jones 1988; Tsukaya and Okada 2012). The discovery of this orchid in Indonesia, especially in Bogor Botanic Gardens was already known by J.J. Smith since 1905 (Smith 1914). Furthermore, the distribution of this orchid is also known in several places such as Sumatera, East Java, Bawean Island, Yogyakarta, and New Guinea (www.gbif.com).
Until now there has been no study to assess the conservation status of $D$. pallens. In Singapore, this species is included in the Nationally Critically Endangered (CR) as mentioned in the Singapore Red Data Book 2nd Edition (Davison et al. 2008). Although this status implies a conservation concern in Singapore that the habitat and population of this orchid have been severely threatened, this is not the case in Indonesia. It is likely due to the lack of detailed information about the ecology of $D$. Pallens.

Generally, D. pallens usually grow on the forest floor and above the ground (Yam and Thame 2005). A previous study located in Bogor Botanic Gardens showed that $D$. pallens was known to only grow under the bamboo clumps (Mursidawati 2004). The morphological appearance of $D$. pallens which has small stature with the absence of photosynthesis, and only rely on small tubers raises the question of how this orchid can survive under a canopy with intense competition.

According to the database of Bogor Botanic Gardens (Ariati et al. 2019), this orchid is not registered as the collection of Bogor Botanic Gardens, meaning that this species is let to grow naturally and not treated as a Botanicplant collection of the garden. Although this orchid can be found in an ex-situ conservation area (i.e. Bogor Botanic Gardens), it does not guarantee the survival of this orchid will be sustainable in the future. This is due to many threats, especially climate change and development around and within Bogor Botanic Gardens. Therefore, to support the conservation of this orchid, it is necessary to know the population and habitat preference of $D$. pallens. This 
research will also reveal whether $D$. pallens has an association with other plants. The result of this study is expected to be used as a basic foundation when developing conservation strategies for terrestrial orchids, especially $D$. pallens. In addition, the results of this study are also expected to provide recommendations for the maintenance of D. pallens at Bogor Botanic Gardens.

\section{MATERIALS AND METHODS}

\section{Study period and area}

The study was conducted in July - October 2019 in Bogor Botanic Gardens, Bogor City, West Java, Indonesia. Data collection on the field consisted of eight sites in Bogor Botanic Gardens bamboo collection (Figure 1). The total number of bamboo stand clumps that are thought to be the natural habitat of $D$. pallens in Bogor Botanic Gardens are 103 clumps of 38 species. The dominant bamboo clump in eight sites was Bambusa spp. (11 species), Gigantochloa spp. (11 species), Dendrocalamus spp. (6 species), Schizostachyum spp. (6 species), Arundinaria spp. (2 species) and other species such as Dinochloa scandens, Melocanna baccifera, Neololeba atra, and Phyllostachys aurea.

\section{Data collection}

Sampling

The study was conducted using purposive sampling method focused on the habitat of the orchid, which was under the bamboo collection. The measurement of environmental variables was done by a systematic transect sampling based on Mueller-Dombois and Ellenberg (1974) with the length of the transect was $2 \mathrm{~m} \times 5 \mathrm{~m}$ (Figure 2). In total, there were eight sampling sites that varied greatly in width, so the number of observation plots was matched to the width of the site. The total observation plots was 82 plots.

\section{Measurement attributes}

Measurements were done on the orchid attributes included orchid densities and the presence of bamboo species where the orchid was found. The environmental attributes recorded were soil humidity and $\mathrm{pH}$, altitude, slope, aspect (the positioning of the sampling plot in a specified direction), litter thickness and the coverage of tree canopy. All variables were measured in the field. The altitude was measured by GPS Garmin. The slope and aspect were measured by Suunto Compass-Clinometer. Soil humidity and $\mathrm{pH}$ were measured by Kelway Soil Tester (Kelway HB-2). Moreover, the coverage of trees canopy was recorded by HabitApp software.

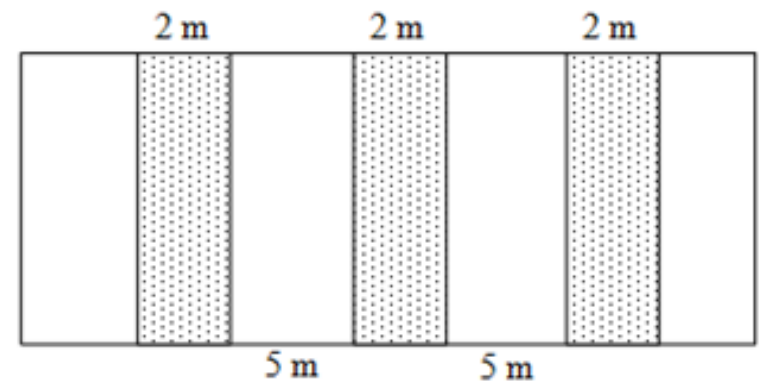

Figure 2. Transect sampling methods
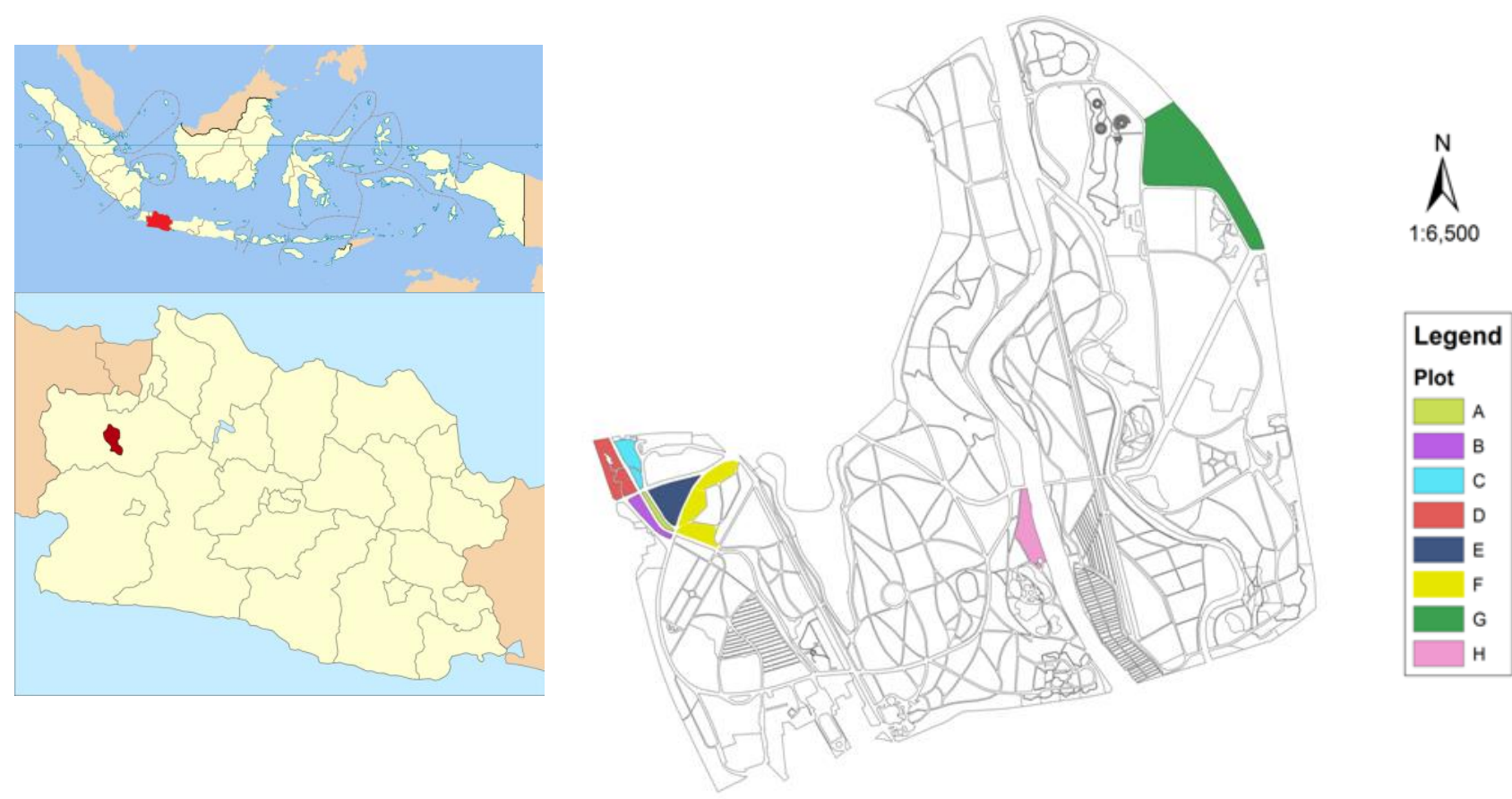

Figure 1. The study sites of the habitat of Didymoplexis pallens in Bogor Botanic Gardens, Bogor City, West Java, Indonesia 
Table 1. Criteria to determine population size based on the number of individuals (modified from Wotavova et al. 2004)

\begin{tabular}{ll}
\hline Range of populations & Number of individuals \\
\hline Small population & $1-10$ \\
Medium population & $11-100$ \\
Large population & $101-1000$ \\
Very large population & $>1001$ \\
\hline
\end{tabular}

\section{Data analysis}

The criteria to determine population size at each plot referred to Wotavova et al. (2004), which is based on the number of individuals found per plot (Table 1). The correlation between the population size of $D$. pallens and the environmental factors in eight sites was analyzed using PCA (Principal Component Analysis). The PCA also determined the components of environmental factors that influenced the presence of $D$. pallens. Determination of the most suitable site for the natural growth of $D$. pallens was analyzed using clustering analysis based on the density of D. pallens. The statistical analyses were performed using IBM SPSS Statistics 26.

\section{RESULTS AND DISCUSSION}

\section{Population of Didymoplexis pallens}

Generally, D. pallens in Bogor Botanic Gardens were found to grow under bamboo clumps. The area of bamboo collections was scattered in eight sites in the gardens (Figure 1). Mostly, the population of D. pallens was found in bamboo leaf litter, but a small population was also found in the bamboo root area (without soil). The height of $D$. pallens ranged from 7 to $20 \mathrm{~cm}$ (Figure 3.A). D. pallens appeared mostly in the flowering stage, with 1,2 or 3 flowers, sometimes with 4 flowers (Figure 3.B). Few of them were also found in the fruiting stage (Figure 3.C). D. pallens dwells from tuber hidden in the ground (Figure 3.D).
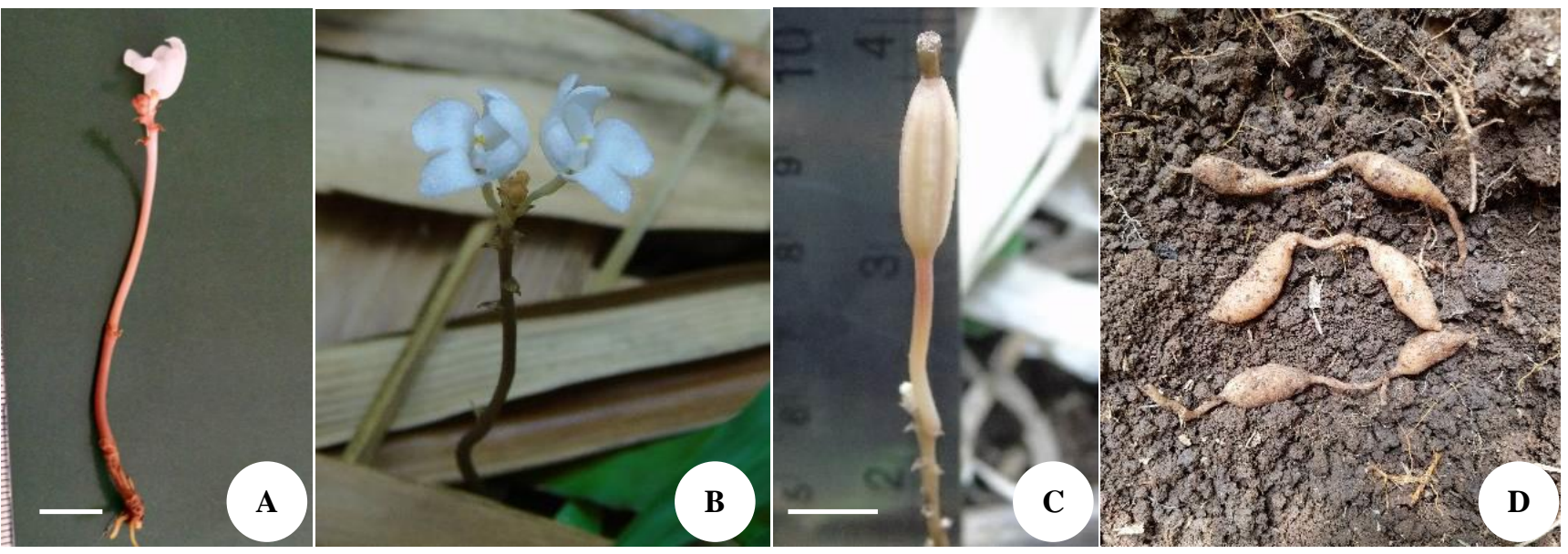

The population of $D$. pallens in Bogor Botanic Gardens had several population fragments at each observation plots. Based on field data, the presence of $D$. pallens was only found at six plots, namely Plots A, B, C, D, E, and G (Table 2). The population size of $D$. pallens at each site can be classified into two sizes, i.e. large population, and small population. Among the six plots inhabited by D. pallens, four plots (i.e. A, B, C, and D) had large population size, ranged between 100-170 individuals per plot with the highest was found in plot $\mathrm{C}$ (170 individuals), while the other two ( $\mathrm{E}$ and $\mathrm{G}$ ) had a very small population. The population of $D$. pallens was not found in two plots (i.e. F and $\mathrm{H})$.

In total, the population of D. pallens found in Bogor Botanic Gardens was 598 individuals. This is almost similar to the $D$. pallens population found in the Northern Territory, Australia that had a large population with 700 individuals (Franklin and Kerrigan 2005). On the other hand, the population of D. pallens in Bogor Botanic Gardens is larger than that in the Indian Botanic Garden, which was about 70 individuals (Rao et al. 1979). Rao et al. (1979) explained that the D. pallens found in the Indian Botanic Garden is included in the rare saprophytic orchid where the orchid springs up in scattered clumps of one few plants amidst wet grass and below the shade of trees.

Table 2. The population of Didymoplexis pallens in Bogor Botanic Gardens

\begin{tabular}{ccl}
\hline Site & $\begin{array}{c}\text { Number of individuals of } \\
\text { D. pallens }\end{array}$ & Population size \\
\hline Plot A & 165 & Large population \\
Plot B & 103 & Large population \\
Plot C & 170 & Large population \\
Plot D & 148 & Large population \\
Plot E & 7 & Small population \\
Plot F & 0 & - \\
Plot G & 5 & Small population \\
Plot H & 0 & - \\
Total & 598 & \\
\hline
\end{tabular}

Figure 3. Didymoplexis pallens in Bogor Botanic Gardens: A. D. pallens habitus; B. Flowering D. pallens in its habitat; C. D. pallens fruit; D. the tuber of $D$. pallens. Bars $=1 \mathrm{~cm}$ 
The growth conditions of this orchid are very dynamic, implying that continuous research needs to be carried out to monitor its growth in Bogor Botanic Gardens. Franklin and Kerrigan (2005) revealed that the majority of the population of $D$. pallens were found dwelling in bamboo leaf litter, some were under other riparian trees, shrubs or vines. However, it is different from the study of $D$. pallens in the Indian Botanic Garden where the orchids were found dwelling under a large exotic tree of Sindora wallichii (Fabaceae) on the edge of Leram Lake (Rao et al. 1979). Thus, it can be concluded that this orchid prefers to dwell under bamboo stands compare to under other plant species. Therefore, maintenance of this orchid's natural habitat needs to be done so that this species remains sustainable in Bogor Botanic Gardens.

\section{Ecology and phytocoenology of Didymoplexis pallens in Bogor Botanic Gardens}

Bamboo collections in Bogor Botanic Gardens are planted in eight sites (Figure 1), which is dominated by the Bambusa spp. and Gigantochloa spp. D. pallens populations were scattered in six sites of the bamboo collection, which is dominated by certain bamboo species included Gigantochloa verticillate, Gigantochloa atroviolacea, Gigantochloa atter, Gigantochloa apus, Dendrocalamus giganteus, Dendrocalamus asper and Bambusa vulgaris (Figure 4). Its population was mostly distributed around three species of bamboo, namely Gigantochloa verticillate (241 individuals), Gigantochloa atroviolacea (145 individuals), and Dendrocalamus giganteus (119 individuals). The presence of $D$. pallens decreased under other bamboo species and belongs to medium population size under Gigantochloa atter (36 individuals), Gigantochloa apus (26 individuals), Bambusa vulgaris (17 individuals), and Dendrocalamus asper (14 individuals). It is different from D. pallens in Mary River Park (estimated 100 individuals) that mostly found under Bambusa arnhemica (Franklin and Kerrigan 2005). Meanwhile, D. pallens populations in the Purwodadi Botanic Garden (174 individuals) were found under three types of Bambusa namely B. jacobsii, B. blumeana, and B. vulgaris (Solikin 2011).

The growth of $D$. pallens in Bogor Botanic Gardens began to appear as several white flowers among the bamboo leaf litter in July and in abundance in August until September (only at the beginning of the rainy season). However, the ecology information was related to the growth of this orchid is still not widely known (Rao et al. 1979; Mursidawati 2004; Franklin and Kerrigan 2005). So, it seems that the growth of $D$. pallens does not require special requirements with certain types of bamboo. Thus, D. pallens has no direct association with certain types of bamboo. However, suitable habitat for these orchids is under the standing of the bamboo community.
Although D. pallens was found in plots with bamboo populations, this orchid was not found growing in observation plots with open conditions exposed to direct sunlight (Figure 5.A) and other ground cover dominance such as wild grasses (Figure 5.B). The same condition is also found in Bukit Timah Nature Reserve in which this orchid grew on the forest floor with a medium canopy cover (Yam and Thame 2005). D. pallens prefers a place to grow with abundant bamboo leaf litter. The presence of bamboo litter keeps the soil humidity, mineral nutrition, and soil microorganisms. Therefore, besides the habitat requirement of $D$. pallens to grow around bamboo, it also prefers a medium shaded habitat and low competition with other plants. According to the result of this study, bamboo leaf litter should be left in D. pallens habitat and other plants or weeds must be cleaned from the area.

\section{Ecological preference of Didymoplexis pallens}

The analysis of ecological preference of habitat characteristics of Didymoplexis pallens was performed using Principal Component Analysis (PCA). The results obtained a KMO (Kaiser-Meyer-Olkin) value that measures the adequacy of sampling. In this study, the value obtained was 0.679 (KMO> 0.5). Moreover, the results of Bartlett's test showed a significance level of 0.000 (p-value <0.05). This explains that the correlation between variable pairs can be explained by other variables. The results of the PCA analysis grouped some important variables that influenced the presence of $D$. pallens along with its percentage of contribution. The results of the analysis divide the abiotic factor into two components, both positive and negative (Table 3). The results of the PCA analysis can be accepted statistically with a condition of value $>0.5$ with a significance of $<0.01$ (Jongman et al. 1987). The positive components indicate a direct relationship to factor interactions (D. pallens), while negative components provide an inverse relationship to factor interactions.

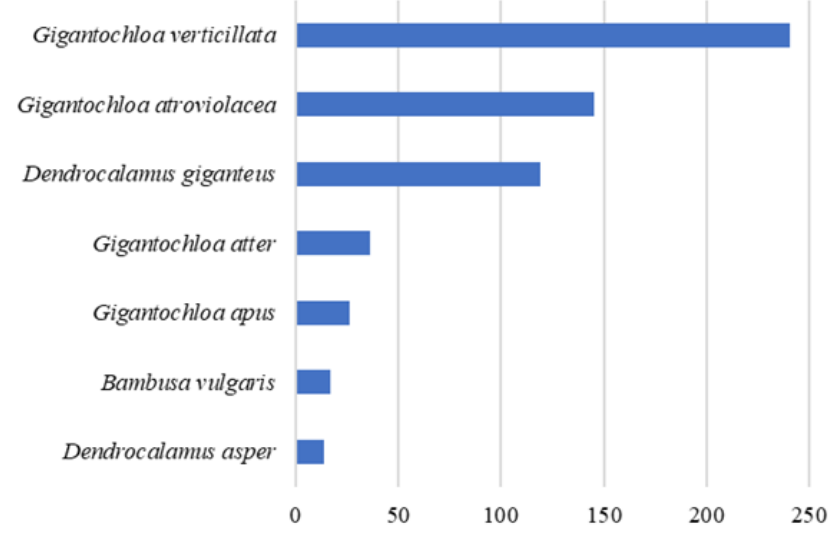

Figure 4. The distribution of Didymoplexis pallens around specific bamboo species in Bogor Botanic Gardens 

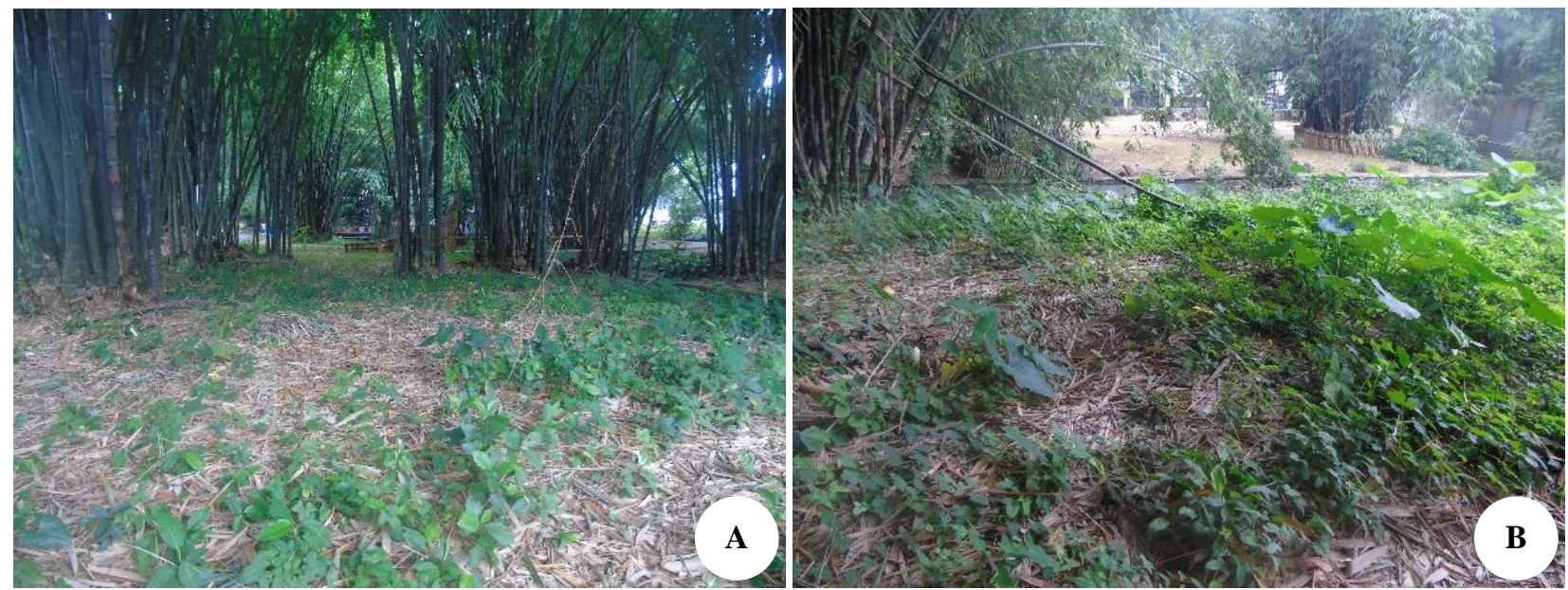

Figure 5. Habitat under bamboo community that is not suitable for Didymoplexis pallens: A. Open space exposed to direct sunlight, B. Site overgrown with weeds

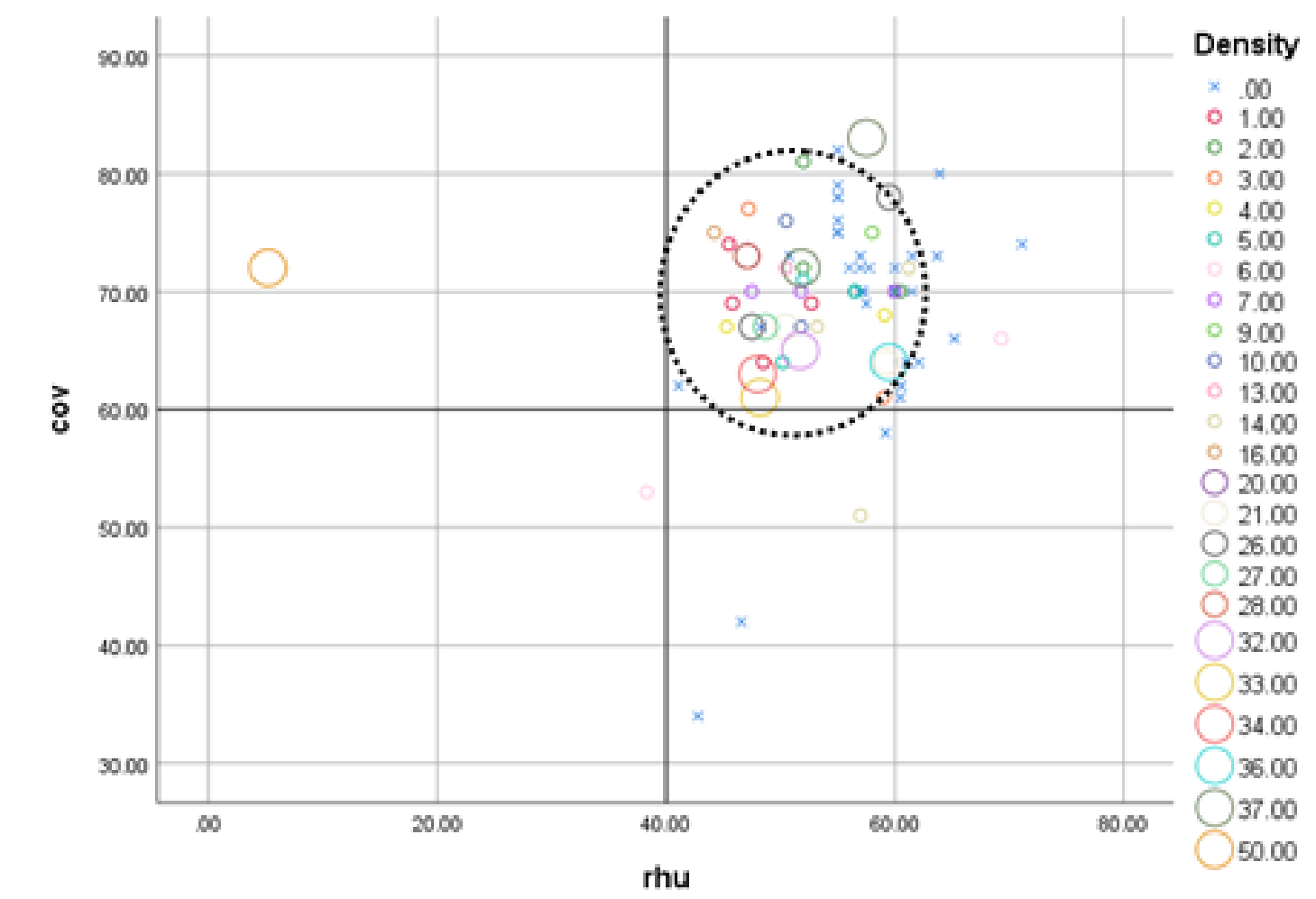

Figure 6. The effect of the first component (i.e. coverage and air humidity) on the presence of Didymoplexis pallens

Table 3. Relationship between Didymoplexis pallens in Bogor Botanic Gardens with the component of environmental factor

\begin{tabular}{llcc}
\hline \multirow{2}{*}{ Environmental factor } & \multirow{2}{*}{ Code } & \multicolumn{2}{c}{ Component } \\
\cline { 3 - 4 } & & $\mathbf{1}$ & $\mathbf{2}$ \\
\hline Coverage & $c o v$ & $\mathbf{. 6 2 2}$ & .309 \\
Soil pH & $p h$ & .213 & $\mathbf{- . 6 8 8}$ \\
Soil humidity & $r h t$ & $\mathbf{- . 7 9 9}$ & -.042 \\
Temperature & $t e m p$ & $\mathbf{. 8 3 7}$ & .023 \\
Air humidity & $r h u$ & $\mathbf{. 6 7 3}$ & -.199 \\
Litter thickness & $L t k$ & .216 & $\mathbf{. 7 3 0}$ \\
\hline
\end{tabular}

Generally, the first component consists of coverage, water humidity, soil humidity, and temperature with the positive components are coverage and water humidity, while negative components are soil humidity and temperature. The second component consists of litter thickness (positive) and soil pH (negative) (Table 3). The first component has a higher percentage in influencing the presence of $D$. pallens. However, in general, the two components are one of the determinants of the presence of D. pallens with a percentage of $56.9 \%$ while the rest are from other factors. 
Environmental factors such as soil humidity, temperature, and soil $\mathrm{pH}$ have a negative correlation with the presence of $D$. pallens (Table 3). This means that this orchid tends not to be found in high soil humidity or waterlogged soil, colder temperatures, and higher soil $\mathrm{pH}$. Environmental factors such as coverage, air humidity, and litter thickness have a positive correlation with the presence of these orchids (Table 3). So, these three environmental factors are closely related to the growth of $D$. pallens, especially in certain ranges (Figure 6). These factors are the preferred condition for the growth of D. pallens, so they cannot be separated because they are interconnected.

D. pallens population preferred shaded areas with a range of $60-80 \%$ coverage and $40-60 \%$ humidity (Figure $6)$. The absence of $D$. pallens was in the humidity $>60 \%$. This value indicates that $D$. pallens do not like areas that are too humid or too dry. This is also supported by studies that say that $D$. pallens only appears at the beginning of the rainy season and will disappear when the rainfall intensity increases (Mursidawati 2004). Observations in Bogor Botanic Gardens suggest that D. pallens did not grow under bamboo stands with heavy shade (relatively dark). Mostly, the abundance of $D$. pallens only existed in relatively light areas (light shade).

Furthermore, ground cover conditions dominated by litterfall from bamboo's leaves are also known to make a major contribution to the existence of $D$. pallens. Therefore, as a terrestrial orchid affected by litter thickness, the presence of litter needs to be maintained in its habitat for the orchid sustainability in the future. This is because D. pallens has tubers that will grow again when the environmental factors are supportive. In addition, litter thickness is thought to have a strong relationship with soil humidity (Nurfadilah 2017) and the supply of soil nutrients (Capelleso et al. 2016). Other soil orchids affected by litter thickness include Plocoglottis lowii (Normagiat et al. 2018) and Didymoplexis striata (Backer and Bakh 1968; Comber 1990).

\section{ACKNOWLEDGEMENTS}

We thank all the staff of Bogor Botanic Gardens, Indonesia for their support, especially Sofi Mursidawati who provided an interesting discussion about the Didymoplexis pallens orchid. We also thank Settama- LIPI for the incentive funds provided so that this paper can be presented at the International Conference of Biodiversity (ICB 2019).

\section{REFERENCES}

Ariati SR, Astuti RS, Supriyatna I, Yuswandi AY, Setiawan A, Saftaningsih D, Pribadi DO. 2019. An alphabetical list of plant species cultivated in the Bogor Botanic Gardens. Center for Plant Conservation and Botanic Gardens- LIPI, Bogor.

Backer CA, Bakhuizen v.d. Brink Jr RC. 1968. Flora of Java (Spermatophytes only) vol. III. Wolters-Noordhoff N.V., Groningen.

Cameron DD, Leake JR. 2007. A different kind of parasitic plant: A brief history of mycoheterotrophy and epiparasitism. Haustoria 51: 4-5.

Capellesso ES, Scrovonski, KL, Zanin EM, Hepp LU, Bayer C, Sausen TL. 2016. Effects of forest structure on litter production, soil chemical composition and litter-soil interactions. Acta Botanica Brasilica 30(3): 329-335.

Comber JB. 1990. Orchids of Java. The Bentham-Moxon Trust, Bangkok. Davison, GWH, Ng PKL, Ho HC. 2018. The Singapore Red Data Book: Threatened Plants and Animals of Singapore. $2^{\text {nd }}$ ed. The Nature Society, Singapore.

Franklin D, Kerrigan R. 2005. A population count and ecological notes for the little-known terrestrial orchid Didymoplexis pallens. Northern Territory Naturalist 18: 51-53.

Hooker JD. 1894 The Flora of British India. Volume 6. Orchidaceae to Cyperaceae. L. Reeve, Ashford, Kent, U.K.

Jones DL. 1998. Native orchids of Australia. Reed, Sydney.

Jongman RHG, ter Braak CJF, van Tongeren, OFR. 1987. Data Analysis in Community and Landscape Ecology. Pudoc, Wageningen.

Leake JR 1994. The biology of myco-heterotrophic ('saprophytic') plants. New Phytol. 127: 171-216

Merckx VSFT, Smets EF, Specht CD. 2013b. Biogeography and conservation. In: Merckx VSFT (ed). Mycoheterotrophy: The biology of plants living on fungi. Springer Science+Business Media, New York.

Merckx VSFT. 2013a. Mycoheterotrophy: An introduction. In: Merckx VSFT (ed). Mycoheterotrophy: The biology of plants living on fungi. Springer Science+Business Media, New York.

Mueller-Dombois D, Ellenberg H. 1974. Aims and Methods of Vegetation Ecology. Blackburn Press, Caldwell, NJ.

Mursidawati S. 2004. Kehidupan Didymoplexis pallens Griffith (Orchidaceae) di habitatnya: sebuah model manajemen konservasi anggrek alam. Warta Kebun Raya 4 (1): 3-8. [Indonesian]

Normagiat S, Harfinda EM, Sudirman S. 2018. Sebaran spasial dan karakteristik habitat anggrek tanah (Plocoglottis lowii Rchb. f.) tumbuhan obat penawar racun asal sanggau Kalimantan Barat. Jurnal Agriovet 1 (1): 37-50. [Indonesian]

Nurfadilah S. 2017. Population study of Peristylus goodyeroides (Orchidaceae) in five habitats and implication for its conservation. Biodiversitas 18 (3): 1084-1091.

Pridgeon AM, Cribb PJ, Chase MW, Rasmussen FN. 2005. Genera Orchidacearum, Vol.4, Epidendroideae (part 1). Oxford University Press, Oxford, UK.

Rao AS, Rathore SR, Srivastava SC. 1979. Didymoplexis pallens Griffrediscovery of a rare saprophytic orchid in the Indian Botanic Garden, Howrah. Nelumbo 21(1-4): 151-155.

Smith, JJ. 1914. Die Orchideen von Java Band IV. Der Flora von Buitenzorg Buchandlung and Druckerei, E.J. Brill, Leiden.

Solikin. 2011. Orchid ecology of Didymoplexis pallen Griffith in Purwodadi Botanic Gardens. Proceeding in Seminar Nasional HUT Kebun Raya Cibodas-LIPI, Cianjur.

Su HJ. 2000. Orchidaceae. In: Huang T-C. et al. (eds.). Flora of Taiwan, 2nd ed. 5: 851-854. Department of Botany, NTU, Taipei, Taiwan.

Tsukaya H, Okada H. 2012. A new variety of Didymoplexis cornuta (Orchidaceae) from West Kalimantan, Borneo. Acta Phytotaxonomica et Geobotanica 62 (2/3): 89-93.

Wotavova K, Balounova Z, Kindlmann P. 2004. Factors affecting persistence of terrestrial orchids in wet meadows and implications for their conservation in a changing agricultural landscape. Biol Conserv 118: 271-279.

Yam TW, Thame A. 2005. Conservation and reintroduction of the native orchids of Singapore. Selbyana 1: 75-80. 